\title{
Individual Differences in Selecting Patients for Regular Hamodialysis
}

\author{
T. R. TAYLOR, J. AITCHISON, L. S. PARKER, M. F. MOORE
}

used-(1) premorbid personality normal; (2) minor anxiety state or depression; (3) inadequate personality; (4) history of recurrent depressions; (5) psychosis; (6) severe personality disorder.

\section{Summary}

Eight clinicians in a renal dialysis unit were asked to classify the suitability of 100 cases (some real, some simulated) for regular haemodialysis. Seven categories were used, ranging from "excellent prospect: accept without reservation" to "unequivocal rejection," based on 18 items of information previously agreed on as sufficient for the purpose. The ways in which they classified the cases differed considerably; only six cases were placed in the same category by all eight clinicians, and this was the "unequivocal rejection" category. Analysis of the extent to which they made effective use of the items showed that between three and nine items were used to a sufficient extent to reach significance for the 100 cases.

\section{Introduction}

The selection of patients for regular dialysis is difficult when demand exceeds resources. Renal dialysis units often have a queue of patients waiting for admission to the regular dialysis programme. Vacancies are created $(a)$ by death, $(b)$ by successful kidney transplantation, or $(c)$ by transfer to home dialysis. The problem of matching the choice of patient to the available resources is complex. Patients are initially admitted for assessment, and over days or weeks a picture is built up of the medical, social, psychological, and economic aspects of each case. In some units the subsequent choice is made by a panel, while in others it is the responsibility of the director of the unit.

\section{Present Study}

The eight clinicians who participated in this study were staff members of the renal dialysis unit of the Royal Infirmary, Glasgow. They ranged from senior house officer to senior registrar and had one to six years' experience of renal medicine. Discussions were held with each clinician to arrive at a set of medical and other items of information which they believed to be sufficient to select patients for regular haemodialysis. Many modifications were made until 18 items (table I) were agreed on by all the participating clinicians and by the director of the unit. Particular attention was paid to partitioning the range for each item to provide (hopefully) something more than an ordinal scale of degree and therefore at least quasi-numerical information throughout. For example, "renal lesion" was recorded using a threepart scale-(1) end-stage or "burnt out" glomerulonephritis, pyelonephritis, polycystic disease; (2) very active, rapidly progressive disease-that is, from $100 \%$ function to nil in four weeks or less; (3) renal lesion part of a generalized disease such as systemic lupus erythematosus. For "psychiatric background" a six-part scale was

University Department of Medicine, Royal Infirmary, Glasgow

T. R. TAYLOR, PH.D., M.R.C.P., Lecturer in Medicine

University of Glasgow, Department of Statistics

J. AITCHISON, M.A., F.R.S.ED., Titular Professor in Statistics

University of Stirling, Department of Psychology

M. F. MOORE, M.A., M.ED., Senior Lecturer in Psychology

L. S. PARKER, M.sC., Research Assistant
TABLE I-Items of Information Provided for Each Case

\begin{tabular}{l|l} 
(1) Renal lesion & (10) Psychiatric background \\
(2) Age & (11) Reliability as a patient \\
(3) Sex & (12) Cardiovascular function \\
(4) Family background & (13) State of vasculature \\
(5) Number of children & (14) Pericarditis \\
(6) Occupation/social class & (15) Optic fundi \\
(7) Annual income & (16) Unal osteodystrophy \\
(8) Employment prospects & (17) Uraemic neuropathy \\
(9) Travelling time to centre & (18) Other disease not related \\
to renal lesion
\end{tabular}

One-hundred cases were assembled, 60 of which were chosen at random from the previous five years' records of patients admitted for assessment for inclusion in the dialysis programme. No account was taken of the decisions that had been made in these cases or of the final outcomes. Because the spread in the values of four of the items family background, psychiatric background, pericarditis, and uraemic neuropathy) for these 60 patients was too restricted for statistical analysis, the remaining 40 cases were simulated so as to include at least one instance of each of the "missing" values but with the same proportional frequencies of values on the other items as in the first 60 . In all cases a value for the patient's income compatible with his occupation and values for travelling time and reliability were added. Finally, all the cases were reviewed by two clinicians not participating in the study and obvious inconsistencies and ambiguities removed. The case sheets were then bound in booklet form.

Each participating clinician was given the booklet and a set of instructions, which began:

This study is aimed at giving us some insight into the way in which individual clinicians use information about their patients in making clinical decisions.

In this booklet there are 100 case records of patients who are to be considered as possible candidates for renal dialysis. A total of 18 items of clinical information are available on each patient.

For the purposes of this study you are to view the patients as if they had been referred from another centre, where the information in the booklet has been assembled after investigation.

In all cases it is assumed that the patients are free of tuberculosis and that their hypertension, if present, is adequately controlled with drugs.

You should complete the cases in groups of 25 in the order indicated on the front of the recording sheet; you may refer back to any of the cases already completed at any time during the experiment. A listing of the coding cystem used in the individual case records is enclosed for refer the at any time during the experiment.

The clinician was also given a response booklet, which asked:

In deciding whether these patients should be chosen for renal dialysis, please indicate the strength of your preference by placing each patient, in
the light of the information given in the case record, in one of the the light of the inform

(A) Excellent prospect: accept without reservation

(B) Good candidate: accept with minor reservation

(C) Borderline pass

(D) Doubtful

(E) Borderline fail

(F) Definite failure, though other centres might accept

(G) Unequivocal rejection.

Choice of category was indicated by encircling one of the letters A-G on the appropriate line in the response booklet. He was given the booklets to take away and asked to carry out the task in his own time in four sessions of 25 cases each, the order of the four blocks of 25 cases being prescribed so as to give a balanced design for the eight subjects when considered together. 


\section{Results}

The classifications of the 100 cases made by the eight clinicians are shown in table II. Each clinician placed only a few cases in category A, and all but clinicians 5 and 6 placed the largest numbers in category $G$. Apart from these two features, however, the ways in which they "used" the categories differed considerably. Clinician 2 placed over half of the cases in category $G$ and made little use of categories D, E, and F. Clinician 4 also placed over half of the cases in category $G$ but made more use of categories D, E, and F. Clinicians 1, 3, and 7 distributed the cases more evenly among categories B to F. Clinician 5 put most cases in categories $C, D$, and E, while clinician 8 used these categories least frequently.

Examination of the number of categories assigned to each case showed that there were only six cases which all eight clinicians placed in the same category, and this was category G. In 32 cases (including these six) the eight assignments were on the same side of category $\mathrm{D}$; seven cases were in $A$ and/or $B$ and/or $C$, while the remaining 25 were in $\mathrm{E}$ and/or $\mathrm{F}$ and/or $\mathrm{G}$. In another 56 cases the assignments were both sides of D-that is, $\mathrm{A}$ and/or $\mathrm{B}$ and/or $\mathrm{C}$ occurred with $\mathrm{E}$ and/or $F$ and/or $G$ among the eight assignments.

Stepwise discriminant analysis ${ }^{1}$ was performed to determine which of the items of information significantly accounted for each clinicians' assignments of the 100 cases among the seven categories-that is, which items significantly accounted for the separation of the cases into the seven subgroups which he had formed. It first determines the item which best separates the seven subgroups, then selects the item which gives the most additional separation, and so on until the remaining items provide no significant further separation. Full allowance for correlations between the items is made.

The items of information that significantly accounted for each clinician's separation of the 100 cases into seven subgroups are listed in table III, the items being arranged in order of the magnitude of their effects. The clinicians clearly differed in the extent to which they made effective use of the 18 items of information. Clinicians 4 and 8 used only three items to an extent sufficient to reach significance for the 100 cases as a group, while clinicians 1 and 3 used seven and nine items respectively. There was measure of agreement, however, on the relative importance of some of the items, age, psychiatric background, cardiovascular function, and other disease being prominent. In interpreting table III one must remember that the list of significant items does not represent the clinician's approach to every (or, indeed, any) individual case; the items listed are those which he considered sufficiently often, and with sufficient weight, to reach significance in accounting for the way he classified this group of 100 cases. The absence of an item from the list does not imply that he did not use it at all but may arise because he did not use it sufficiently often and with sufficient weight for it to reach significance for the group of 100 cases, or because its effective contribution was contained in one or more correlated items occurring in higher positions in the list.

TABLE II-Classifications of the 100 Cases by the Eight Clinicians

\begin{tabular}{|c|c|c|c|c|c|c|c|c|}
\hline \multirow{2}{*}{ Category } & \multicolumn{8}{|c|}{ Clinician } \\
\hline & 1 & 2 & 3 & 4 & 5 & 6 & 7 & 8 \\
\hline $\begin{array}{l}\mathbf{A} \\
\mathbf{B} \\
\mathbf{C} \\
\mathbf{D} \\
\mathbf{E} \\
\mathbf{F} \\
\mathbf{G}\end{array}$ & $\begin{array}{r}3 \\
11 \\
10 \\
10 \\
12 \\
22 \\
32\end{array}$ & $\begin{array}{r}4 \\
13 \\
25 \\
1 \\
0 \\
1 \\
56\end{array}$ & $\begin{array}{r}3 \\
11 \\
13 \\
13 \\
13 \\
20 \\
27\end{array}$ & $\begin{array}{r}1 \\
5 \\
9 \\
11 \\
9 \\
7 \\
58\end{array}$ & $\begin{array}{r}1 \\
6 \\
20 \\
25 \\
19 \\
14 \\
15\end{array}$ & $\begin{array}{r}7 \\
13 \\
15 \\
4 \\
27 \\
20 \\
14\end{array}$ & $\begin{array}{r}7 \\
16 \\
17 \\
14 \\
11 \\
8 \\
27\end{array}$ & $\begin{array}{r}7 \\
22 \\
7 \\
9 \\
5 \\
19 \\
31\end{array}$ \\
\hline
\end{tabular}

\section{Discussion}

In practice clinicians are not confronted with 100 cases but with only one or two at a time; and they meet them face-to-face over a period, thus having more opportunity of assimilating the relevant items of information than in this study. Furthermore, our use of seven categories instead of the two-accept and reject-which may more commonly be used undoubtedly tends to magnify differences in classification. If we had given the clinicians only two categories the lists of significant items in table III might have been shorter. But not all the differences can be dismissed as an artefact of a more demanding task or attributed to differences in experience; some must be real in a deeper sense.

What should be done about them ? Differences could probably be "resolved" to some extent by face-to-face discussion among the clinicians about the importance of the items of information in general or about their values in each particular case. Following the pioneer work of Asch, ${ }^{2}$ Tuddenham ${ }^{3}$ and many others have clearly shown that we should be suspicious of this kind of resolution, since it is more likely to result from the social pressures of the discussion situation and should be viewed as social conformity rather than as convergence of judgement. Until there is a satisfactory criterion for what constitutes a "correct" classification, or of whether one selection is "better" than another, there is merit in diversity of approach and safety in disagreement in classifying the patients. There may be many difficulties in quantifying the outcome of assigning a patient to regular dialysis and the outcome of not doing so, particularly in assessing the quality of the patient's survival, but some headway must be made in this direction before we can begin to ignore the risks inherent in removing the existing differences of judgement.

If the differences between the clinicians in this study are typical it is clearly desirable (as is done in this unit and many others) to collect the independent judgements of several clinicians and other members of the unit team. The judgements may be combined by taking a simple majority or some other measure of centrality. When ties occur further members can be added to the panel to resolve them. In this way some consistency in classifications is obtained from one occasion to another, though the members of the panel may change; a consistency which in the light of the differences we found seems most unlikely to be achieved when changing from one individual member to another.

We thank Professor A. C. Kennedy and the staff of the renal dialysis unit of the Royal Infirmary, Glasgow, for their collaboration in this study.

\section{References}

1 Dixon, W. J., Biomedical Computer Programs. Berkeley, California, 1967. 2 Asch, S. E., in Groups, Leadership and Men, ed. H. Guetzkow. Pittsburgh,

3 Tuddenham, R. D., fournal of Psychology, 1958, 46, 22.

TABLE III-Items of Information which Significantly Accounted for Each Clinician's Separation of the 100 Cases into Seven Subgroups Arranged in Order of Magnitude of their Effects

\begin{tabular}{|c|c|c|c|c|c|c|c|}
\hline \multicolumn{8}{|c|}{ Clinician } \\
\hline 1 & 2 & 3 & 4 & 5 & 6 & 7 & 8 \\
\hline $\begin{array}{l}\text { Optic fundi } \\
\text { Psychiatric } \\
\text { background } \\
\text { Cardiovascular } \\
\text { function } \\
\text { Renal lesion } \\
\text { Age } \\
\text { Renal osteodystrophy } \\
\text { Employment } \\
\text { prospects }\end{array}$ & $\begin{array}{l}\text { Age } \\
\text { Other disease } \\
\text { Psychiatric } \\
\text { background } \\
\text { Sex }\end{array}$ & $\begin{array}{l}\text { Cardiovascular } \\
\text { function } \\
\text { Renal lesion } \\
\text { Other disease } \\
\text { Sex } \\
\text { Psychiatric } \\
\text { background } \\
\text { Number of } \\
\text { children } \\
\text { Employment } \\
\text { prospects } \\
\text { Age } \\
\text { Renal } \\
\text { osteodystrophy }\end{array}$ & $\begin{array}{l}\text { Age } \\
\text { Cardiovascular } \\
\text { function } \\
\text { Other disease }\end{array}$ & $\begin{array}{l}\text { Age } \\
\text { Annual income } \\
\text { Psychiatric } \\
\text { background } \\
\text { Renal } \\
\text { osteodystrophy }\end{array}$ & $\begin{array}{l}\text { Age } \\
\text { Psychiatric } \\
\text { background } \\
\text { Other disease } \\
\text { Renal lesion } \\
\begin{array}{c}\text { Renal } \\
\text { osteodystrophy }\end{array}\end{array}$ & $\begin{array}{l}\text { Age } \\
\text { Renal } \\
\text { osteodystrophy } \\
\text { Psychiatric } \\
\text { background } \\
\text { Optic fundi } \\
\text { Annual income }\end{array}$ & $\begin{array}{l}\text { Psychiatric } \\
\text { background } \\
\text { Age } \\
\text { Other disease }\end{array}$ \\
\hline
\end{tabular}

